\title{
Seasonal patterns of parasitism of the tropical spiders Theridion evexum (Araneae, Theridiidae) and Allocyclosa bifurca (Araneae, Araneidae) by the wasps Zatypota petronae and Polysphincta gutfreundi
} \section{(Hymenoptera, Ichneumonidae)}

\author{
Gilbert Barrantes $^{1}$, William G. Eberhard ${ }^{1,2} \&$ Ju-Lin Weng ${ }^{1,3}$ \\ 1. Escuela de Biología, Universidad de Costa Rica, San José, Costa Rica, Fax: 207-4216; gilbert.barrantes@gmail.com \\ 2. Smithsonian Tropical Research Institute, Panama. \\ 3. Department of Entomology, Kansas State University, Manhattan KS 66506.
}

Received 05-II-2007. C Corrected 23-X-2007. Accepted 29-IV-2008.

\begin{abstract}
The rates of parasitism of Theridion evexum by the parasitoid wasp Zatypota petronae, and Allocyclosa bifurca by Polysphincta gutfreundi, were followed for two years. Parasitism of T. evexum was very low (mean $1.39 \pm 1.8 \%$ ), and restricted to nearly seven months of the year. Parasitism of $A$. bifurca was higher (mean 7.8+7.6\%), and did not show a seasonal pattern. Reproduction of the host spider T. evexum was highly seasonal, with only one, highly coordinated generation per year, while adults of A. bifurca were present year round. Short-term autocorrelation on parasitism rates over time at different sites suggest that $P$. gutfreundi tend to return to the same sites to hunt hosts over periods of a few weeks. Rev. Biol. Trop. 56 (2): 749-754. Epub 2008 June 30.
\end{abstract}

Key words: Parasitism rate, parasitoids, koinobiont wasps, Theridiidae, Araneidae, Ichneumonidae.

The Polysphinctini are koinobiont ectoparasitoid ichneumonid wasps that attack spiders in several families (Nielsen 1923, 1932a, b, Fincke et al. 1990, Gauld and Shaw 1995, Gauld et al. 1998). Rates of parasitism by polysphinctine wasps have seldom been studied; fragmentary data for tropical species suggest that parasitism rates vary among species, among populations, and between years (Fincke et al. 1990, Eberhard 2000a, b, Weng and Barrantes 2007).

Available data suggest that each polysphinctine wasp species attacks one or a few related spider species (Gauld et al. 1998, Hanson and Gauld 2006). Hence the life cycle and population size of different parasitoid species may be adjusted to the biology and changes in population size of their hosts. We describe the temporal variation in parasitism rate of two polysphinctine wasp species:
Zatypota petronae Gauld and Polysphincta gutfreundi Gauld on their respective hosts, Theridion evexum Keyserling (Theridiidae) and Allocyclosa bifurca (McCook) (Araneidae) in the Central Valley of Costa Rica.

Theridium evexum constructs webs in the undergrowth of wet forests and associated secondary growth (Barrantes and Weng 2007). Its web has a green leaf folded to form a cone that is used by the spider as a retreat. Additionally, a small tangle, from which multiple long sticky lines extend mainly downward to other leaves, is constructed near the retreat opening (Barrantes and Weng 2007). Allocyclosa bifurca builds orb webs attached primarily to large, rigid, long-lived leaves, especially those of plants in the family Agavacea (e.g. Yucca spp., Agave spp.); they also occur on buildings and bromeliads (Eberhard 2003). 


\section{MATERIALS AND METHODS}

We censused spiders and parasitoid eggs and larvae on their abdomens (and also parasite pupae in their webs in the case of $Z$. petronae) approximately every two weeks from Octuber 2004 to October 2006 (for T. evexum) and from December 2003 to May 2006 (for A. bifurca) on the campus of the Universidad de Costa Rica, San Jose Province ( $9^{\circ} 54^{\prime}$ N, $84^{\circ} 03^{\prime}$ W; elevation $1100 \mathrm{~m}$ ). The campus is located on the western region of the Central Valley where the mean annual precipitation is $1900 \mathrm{~mm}$ and the mean annual temperature $20^{\circ} \mathrm{C}$, with a dry season from December through March (Bergoeing 1998). All juveniles and adults T. evexum were censused in one plot of $250 \mathrm{~m}^{2}$ of secondary forest in the Reserva Biologica Leonel Oviedo. We counted adults and subadults of $A$. bifurca, mostly on large, solitary individuals or small groups of Agavaceae plants scattered over the campus. The most distant places were separated by approximately $300-400 \mathrm{~m}$. The total number of sites that were surveyed varied from four to six, as some plants died or were cut and removed, and other sites with spiders were discovered during the study.

Because the development time of the wasps from egg to pupa was less than two weeks (G. Barrantes and J. L. Weng unpub., W. G. Eberhard unpub.), parasitoids were not counted twice in different censuses. Parasitism rates were thus at least potentially independent between successive censuses. Autocorrelation analyses were performed on the percentage parasitism of $A$. bifurca between censuses for four different sites. This analysis allowed us to examine whether parasitism rates were independent between successive censuses. Low values of the parameter $\eta$ (significantly lower than 2) indicate non-random consecutive sequences of low or high values (e.g., several consecutive censuses with high parasitism followed by several consecutive censuses with low parasitism), whereas high values of the same parameter (significantly higher than 2) indicate dependence between values of consecutive censuses (Sokal and Rohlf 1995: 393-396). Additionally, percentage of parasitism was scored at four different sites (separated by 100 to $400 \mathrm{~m}$ ) for each census, during 46 censuses. The site with highest parasitism received a score of 4 , whereas the site with lowest parasitism received a score of 1 . Scores of the different sites were analyzed using a Friedman test. Specimens of spiders and wasps were deposited in the Museo de Zoología, Universidad de Costa Rica.

\section{RESULTS}

Population size: The population of $T$. evexum showed extreme annual seasonal fluctuations that were similar during both years (Fig. 1) (Kolmogorov-Smirnov $=0.002, p>$ 0.20). Egg sacs began to appear in the retreats in August, and were present until January or February. During this period (the end of the wet season and the beginning of the dry season), the population was lowest, and consisted of almost exclusively adult females. The population was consisted almost completely of juvenile individuals when it began to increase in DecemberJanuary, and reached a maximum in May - July, then decreased steadily until the next reproductive period began.

The censuses of $A$. bifurca were less representative of the population of spiders, as they included only adult and subadult females (males are quite small, and subadult males were not counted), and the number of sites where spiders were censused varied. Thus particular peaks and valleys in Figure 3 are not necessarily biologically significant. It was clear; however, that adult and subadult females were present at all times of the year. A similar pattern was observed when censuses at some sites were analyzed independently.

Percentage of parasitism: The mean rate of parasitism of T. evexum was $1.39 \pm 1.80 \%$, and did not exceeded $7.7 \%$ in any census. Parasites were only found on larger immature spiders, and thus occurred during the second half of each annual peak of abundance (Fig. 1). Parasites were only found on larger immature spiders 


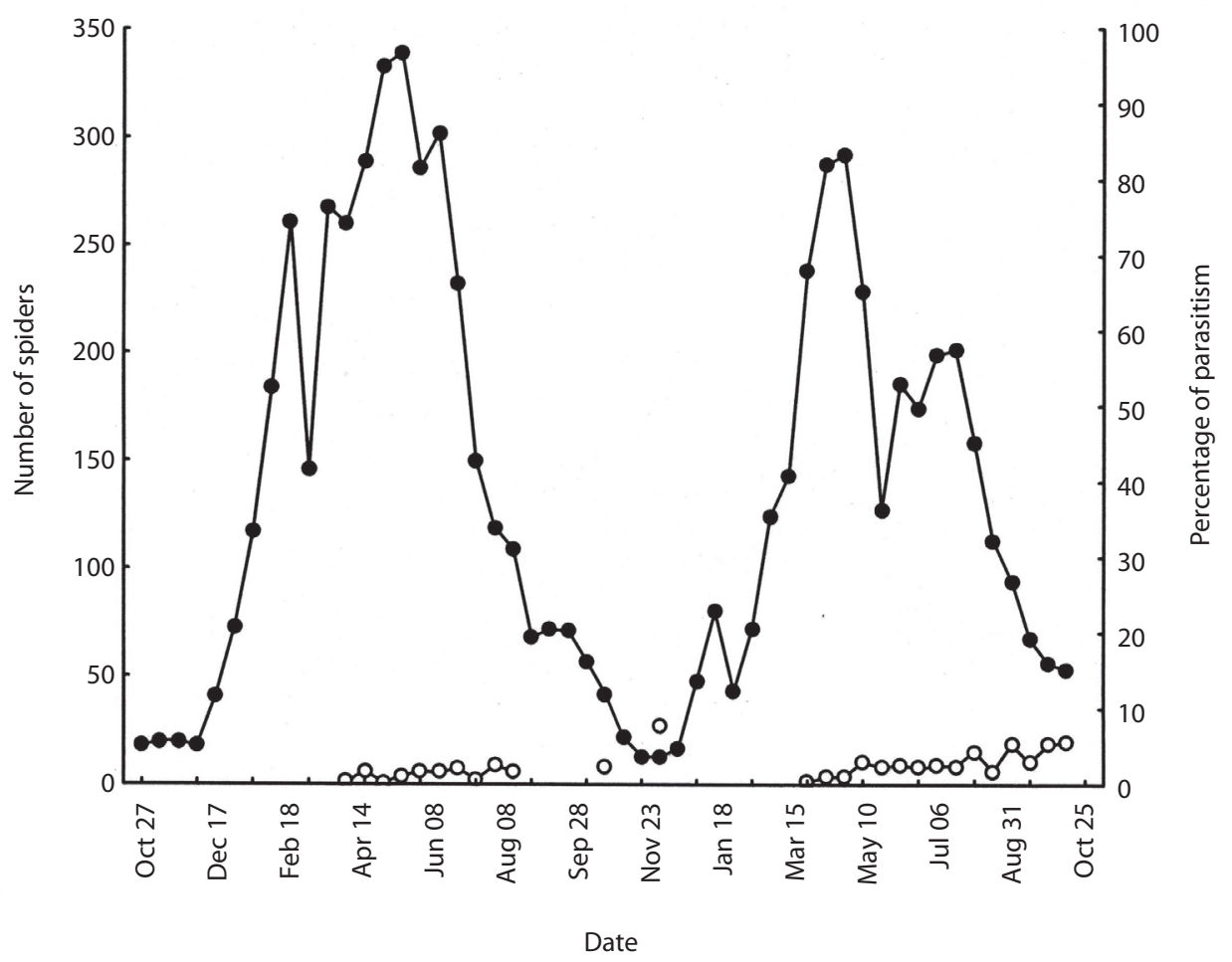

Fig. 1. Temporal changes in number of spiders (filled circles) and percentage of parasitism (open circles) of Theridion evexum, from Octuber 2004 to October 2006 on the campus of the Universidad de Costa Rica, San Jose Province.

(apparently fourth instar up to subadults), and thus occurred during the second half of each annual peak of abundance (Fig. 1); they were not present on adults or younger spiderlings. Parasitism in A. bifurca was much higher, with an overall mean of $7.8 \pm 7.6 \%$ and a maximum of $29.6 \%$. Parasitized spiders were found in most censuses (Fig. 2), and parasites were found only on subadult and adult females.

In both spider species, the rate of parasitism was not related to the size of their population (T. evexum: $\mathrm{r}=-0.001, \mathrm{p}=.99, \mathrm{n}=55 ; A$. bifurca: $\mathrm{r}=0.13, \mathrm{p}=0.28, \mathrm{n}=68$ ). Analyzing four different sites separately for A. bifurca, in only one was the parastism rate correlated with population size $(\mathrm{r}=0.28, \mathrm{p}=0.027, \mathrm{n}=62)$.

Parasitism rates varied significantly over time. Autocorrelation analyses showed that both species tended to show periods with low rates in successive censuses, and other periods with successive high rates (Table 1). Separate analyses of $A$. bifuca parasitism at different sites showed the same trend in three of four sites (sites 1 to 3 ) with sufficient samples (Table 1), the fourth site had the lowest mean spider number and its parasitism rate did not differ from what was expected from random (Table 1). Furthermore, over-time rate of parasitism was significant higher at the site 1 and lower at the site 4 (Friedman test: $X^{2}=9.76, n$ $=46, \mathrm{df}=2, \mathrm{p}<0.02$; Fig. 3 ).

\section{DISCUSSION}

The two pairs of host and parasitoid studied represent two different patterns in the population dynamics of tropical species: a highly seasonal fluctuation in which the populations of the host and the parasitoid are more or less in synchronized; and a relatively nonseasonal host whose parasitoid also shows little 


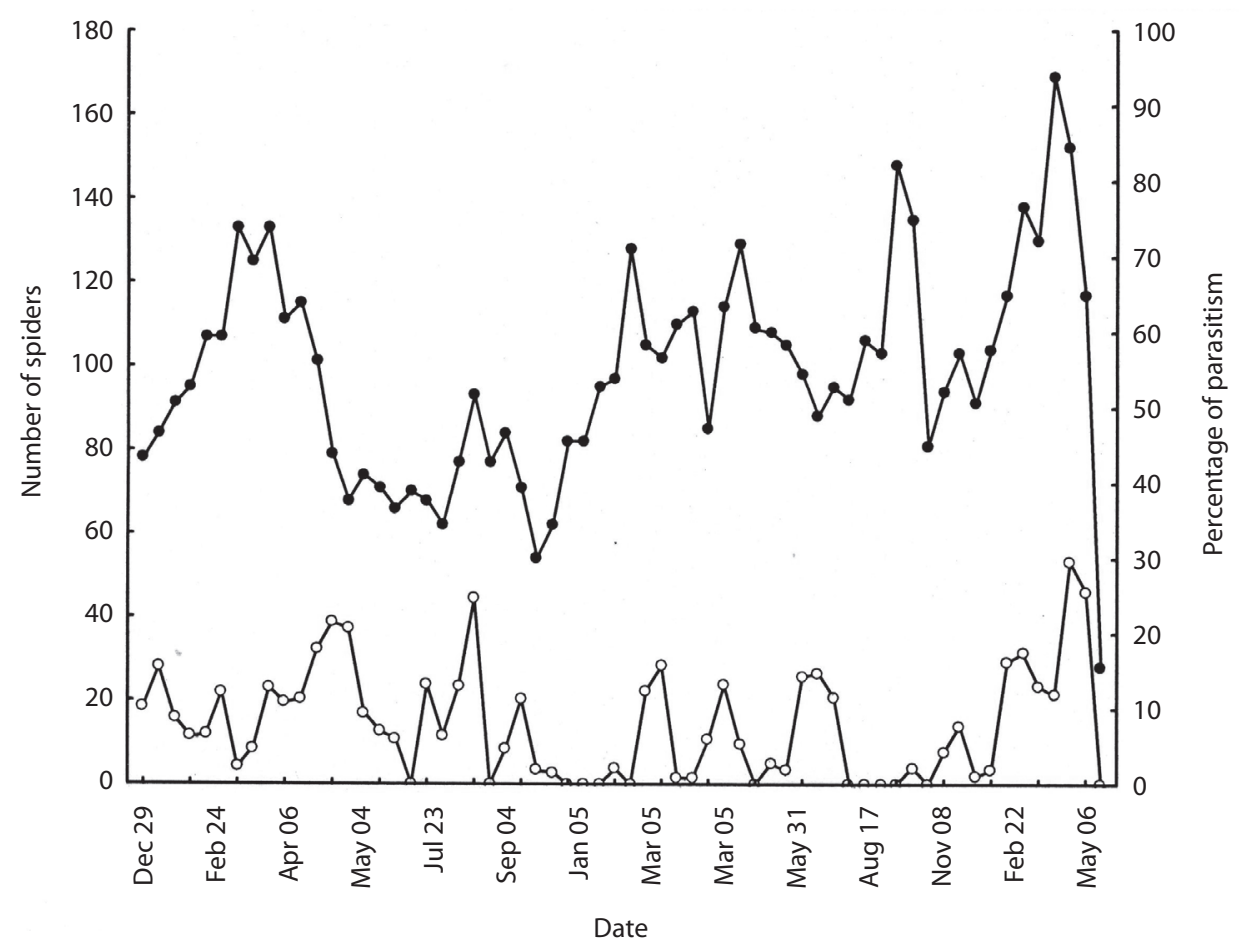

Fig. 2. Number of subadult and adult females (filled circles) of Allocyclosa bifurca and the percentage of parasitism (open circles), from December 2003 to May 2006 on the campus of the Universidad de Costa Rica, San Jose Province.

TABLE 1

Results of autocorrelation analyses for Theridion evexum and Allocyclosa bifurca (total and different patches). Mean and standard deviation for the percentage of parasitism and for the number of spiders per census are included in the columns seventh and eighth respectively

$\begin{array}{lccccccc}\text { Species } & \text { Site } & \eta & \text { t student } & \mathrm{P} & \mathrm{N} & \text { \% parasitism } & \text { No. spiders } \\ \text { T. } \text { evexum } & \text { total } & 1.09 & 3.43 & <0.01 & 53 & 1.39 \pm 1.8 & 132.2 \pm 99.2 \\ \text { A. bifurca } & \text { total } & 1.29 & 2.95 & <0.01 & 68 & 7.8 \pm 7.6 & 93.9 \pm 14.3 \\ \text { A. bifurca } & \text { one } & 1.40 & 2.39 & <0.01 & 62 & 10.7 \pm 13.7 & 33.6 \pm 23.4 \\ \text { A. bifurca } & \text { two } & 1.20 & 3.20 & <0.01 & 46 & 7.2 \pm 14.3 & 23.0 \pm 13.4 \\ \text { A. bifurca } & \text { three } & 1.47 & 2.12 & <0.05 & 62 & 7.1 \pm 10.6 & 18.8 \pm 6.1 \\ \text { A. bifurca } & \text { four } & 1.79 & 0.83 & >0.40 & 61 & 2.9 \pm 6.2 & 14.7 \pm 6.1\end{array}$

Less than 2 significant values of the parameter $\eta$ indicate sequences of low (high) incidence of parasitism followed by sequences of high (low) incidence of parasitism.

T student- test whether values of consecutive sensuses are independent $(\eta=2)$; P- is the probability associated to $t$ student values; $\mathrm{N}$ - number of censuses included in each case. 


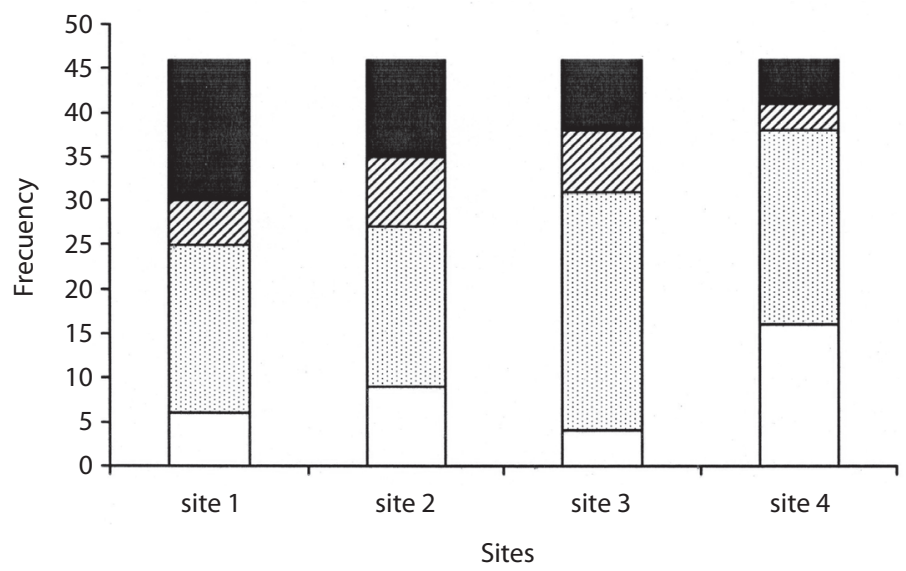

Fig. 3. Number of census scored by their intensity of parasitism (Polysphincta gutfreundi on Allocyclosa bifurca).Black boxes indicate highest parasitism, white boxes lowest, and other boxes indicate intermediate levels of parasitism. Number of censuses were 46 in all sites.

seasonality. The highly seasonal reproduction of $T$. evexum resulted in a complete absence of appropriately sized hosts for $Z$. petronae during about 5 months of the year (Fig. 1). We suggest that $Z$. petronae may have another host species that it uses during at least this portion of the year. In contrast, A. bifurca was present year round, and it was parasitized by $P$. gutfreundi throughout the year.

The spider $A$. bifurca is unusual in having extremely low rates of movement between web sites; the mean residence time for marked mature females in one study was nearly eight weeks (Eberhard 2003). In addition, the distribution of spiders among different plants was quite patchy. Some particular plants that had a large population of $A$. bifurca ( $>30$ individuals) at one stage of this study were nearly deserted at others, despite the presence of substantial numbers of spiders on nearby plants. Similar patterns of fluctuation also occurred on different portions at another site in the Central Valley (near San Antonio de Escazu, 1300 m, W. G. Eberhard, unpubl.). The patchiness of the parasitism of $A$. bifurca by $P$. gutfreundi at different sites at any given time of the year may be linked to these two traits of the host, low rates of movement and spider patchy distribution. We suspect that the parasitism patchiness results from a given female wasp learning and then returning to a particular patch of hosts day after day (Lessells 1985, Godfray 1993), particularly when patches have relatively high densities of spiders (Table 1). We have seen on three occasions a female wasp attack several spiders on a given plant in the space of less than an hour (W. G. Eberhard in prep.).

Considering the little climatic fluctuation in the tropics (Cavelier and Vargas 2002), it is somewhat unexpected the temporal population dynamics showed by T. evexum. The population dynamic of this species closely resembles the dynamic of many temperate (Andrewartha and Birch 1982) or more seasonal tropical organisms (Robinson and Robinson 1973, Robinson and Lubin 1979, Janzen 1983). This suggests that relatively small climatic changes could trigger reproduction in $T$. evexum, but it has not apparently effect on the reproduction of $A$. bifurca. However, long-term studies are needed to elucidate the effect of seasonal climatic changes on the reproduction of these tropical spider species.

\section{ACKNOWLEDGEMENTS}

We thank Luis Sandoval for helping with field work. Financial support was provided by the Universidad de Costa Rica. 


\section{RESUMEN}

Las tasas de parasitismo de Theridion evexum por la avispa parasitoide Zatypota petronae y de Allocyclosa bifurca por Polysphincta gutfreundi fueron estudiadas durante dos años. El parasitismo en T. evexum fue muy bajo (promedio $1.39 \pm 1.8 \%$ ) y restringido a aproximadamente siete meses del año. El parasitismo en $A$. bifurca fue más alto (promedio $7.8+7.6 \%$ ) y no mostró un claro patrón estacional. La reproducción de la araña hospedera $T$. evexum fue muy estacional, con solamente una generación por año, mientras que los adultos de $A$. bifurca estuvieron presentes todo el año. Autocorrelaciones de las tasas de parasitismo entre censos consecutivos en diferentes sitios sugiere que $P$. gutfreundi tiende a retornar a los mismos sitios para parasitar las arañas hospederas durante algunas semanas.

Palabras clave: Tasa de parasitismo, parasitoides, avispas koinobiontes, Theridiidae, Araneidae, Ichneumonidae

\section{REFERENCES}

Andrewartha, H. G. \& L. C. Birch. 1982. Selection from the distribution and abundance of animals. University of Chicago, Chicago, Illinois, USA.

Barrantes, G. \& J. L. Weng. 2007. Natural history, courtship, feeding behaviour and parasites of Theridion evexum (Araneae: Theridiidae). Bull. British Arachnol. Soc. 14: $61-65$.

Bergoeing, J. P. 1998. Geomorfología de Costa Rica Instituto Geográfico Nacional. San José, Costa Rica.

Cavelier, J. \& G. Vargas. 2002. Procesos hidrológicos. pp. 145 - 165. In M. R. Guariguata \& G. H. Kattan (eds.), Ecología y conservación de bosques tropicales. Tecnológica de Costa Rica, Cartago, Costa Rica.

Eberhard, W. G. 2003. Substitution of silk stabilimenta for egg sacs by Allocyclosa bifurca (Araneae: Araneidae) suggests that silk stabilimenta function as camouflage devices. Behaviour 140: 847 - 868 .

Eberhard, W. G. 2000a. The natural history and behavior of Hymenoepimecis argyraphaga (Hymenoptera: Ichneumonidae) as parasitoid of Plesiometa argyra (Araneae: Tetragnathidae). J. Hym. Res. 9: 220 240 .

Eberhard, W. G. 2000b. Spider web manipulation by a wasp larva. Nature 406: 255 - 256.

Fincke, O. M., L. Higgins, \& E. Rojas. 1990. Parasitsm of Nephila clavipes (Araneae: Tetragnathidae) by an ichneumonid (Hymenoptera, Polysphinctini) in Panama. J. Arachnol. 18: 321 - 329.

Gauld, I. D., J. A. Ugalde G. \& P. Hanson. 1998. Guía de los Pimplinae de Costa Rica (Hymenoptera: Ichneumonidae). Rev. Biol. Trop. 46 (Supl. 1): 1 189.

Godfray, H. C. J. 1993. Parasitoids. Behavioral and evolutionary ecology. Princeton University, Princeton, New Jersey, USA.

Gauld, I. D. \& S. R. Shaw. 1995. The ichneumonoid families. pp. 389 - 431. In P. E. Hanson \& L. D. Gauld (eds.), The Hymenoptera of Costa Rica. Oxford University, Oxford, United Kingdom

Hanson, P. E. \& I. D. Gauld. 2006. Hymenoptera de la Región Neotropical. American Entomological Institute, Gainesville, Florida, USA.

Janzen, D. H. 1983. Insects. pp. 619 - 650. In D.H. Janzen (ed.), Costa Rican natural history. The University of Chicago Press, Chicago, Illinois, USA.

Lessells, C. M. 1985. Parasitoid foraging: should parasitism be density dependent? J. Anim. Ecol. 54: 27 - 41 .

Nielsen, E. 1923. Contributions to the life history of the Pimpline spider parasites (Polysphincta, Zaglyptus, Tromatobia) (Hym. Ichneum.). Entomologisk Forening 14: $10-205$.

Nielsen, E. 1932a. The biology of spiders. Vol. 1. Levin \& Munksgaard. Copenhagen, Denmark.

Nielsen, E. 1932b: The biology of spiders. Vol. 2. Levin \& Munksgaard. Copenhagen, Denmark.

Robinson, M. H. and Y. D. Lubin. 1979. Specialists and generalists: the ecology and behavior of some webbuilding spiders from Papua New Guinea. Pac. Ins. 21: $133-164$

Robinson, M. H. \& B. Robinson. 1973. Ecology and behavior of the Giant Wood Spider Nephila maculata (Fabricius) New Guinea. Smithson. Contrib. Zool. 149: 1-76.

Sokal, R. R. \& F. J. Rohlf. 1995. Biometry. W. F. Freeman, New York, USA.

Weng, J. L. \& G. Barrantes. 2007. Natural History and Larval Behavior of the parasitoid Zatypota petronae (Hymenoptera: Ichneumonidae). J. Hym. Res. 16: 327-336. 